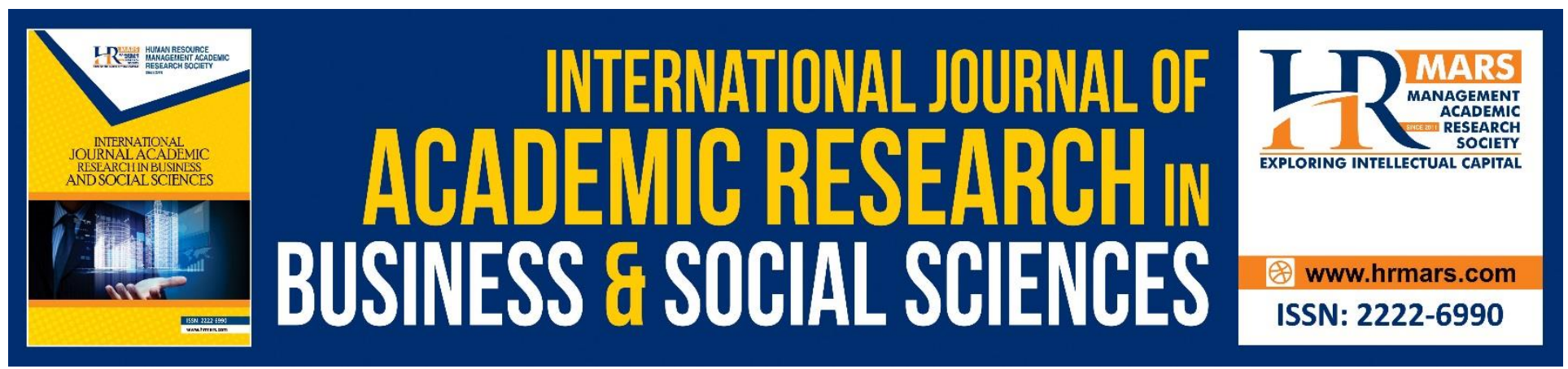

\title{
A Critique of Normative Commitment in Management Research
}

\author{
Hamid Masud, Wan Norhayate Wan Daud, Fakhrul Anwar Zainol, \\ Norfadzilah Rashid, Asyraf Afthanorhan
}

To Link this Article: http://dx.doi.org/10.6007/IJARBSS/v8-i11/5161

DOI: $10.6007 /$ IJARBSS/v8-i11/5161

Received: 18 Oct 2018, Revised: 21 Nov 2018, Accepted: 03 Dec 2018

Published Online: 04 Dec 2018

In-Text Citation: (Masud, Daud, Zainol, Rashid, \& Afthanorhan, 2018)

To Cite this Article: Masud, H., Daud, W. N. W., Zainol, F. A., Rashid, N., \& Afthanorhan, A. (2018). A Critique of Normative Commitment in Management Research. International Journal of Academic Research in Business and Social Sciences, 8(11), 1172-1191.

Copyright: (c) 2018 The Author(s)

Published by Human Resource Management Academic Research Society (www.hrmars.com)

This article is published under the Creative Commons Attribution (CC BY 4.0) license. Anyone may reproduce, distribute, translate and create derivative works of this article (for both commercial and non-commercial purposes), subject to full attribution to the original publication and authors. The full terms of this license may be seen

at: http://creativecommons.org/licences/by/4.0/legalcode

Vol. 8, No. 11, 2018, Pg. 1172 - 1191

http://hrmars.com/index.php/pages/detail/IJARBSS

JOURNAL HOMEPAGE

Full Terms \& Conditions of access and use can be found at http://hrmars.com/index.php/pages/detail/publication-ethics 


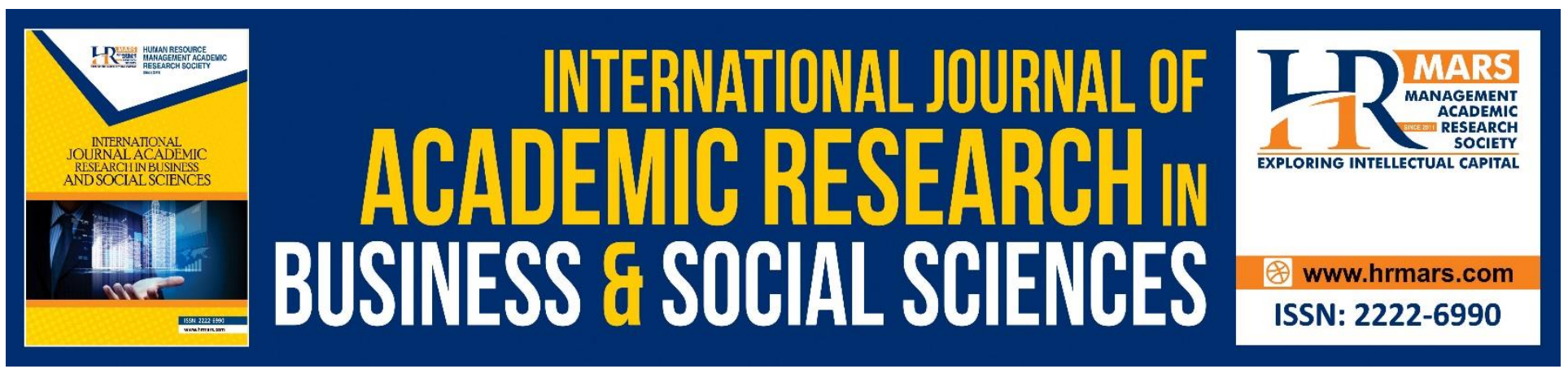

\title{
A Critique of Normative Commitment in Management Research
}

\author{
${ }^{1}$ Hamid Masud, ${ }^{2}$ Wan Norhayate Wan Daud, ${ }^{3}$ Fakhrul Anwar Zainol, \\ ${ }^{4}$ Norfadzilah Rashid, ${ }^{5}$ Asyraf Afthanorhan \\ 2,3,4,5Faculty of Economics and Management Sciences, Universiti Sultan Zainal Abidin, \\ 21300 Kuala Nerus, Terengganu, Malaysia \\ ${ }^{1}$ COMSATS University (Virtual Campus), Islamabad, Pakistan \\ Corresponding Author: wnhayate@unisza.edu.my
}

\begin{abstract}
Commitment plays an essential role in organizing work outcomes. As long as employees show commitment to the organization, favorable outcomes can be seen. When specific factors lead towards dissatisfaction of employees, it results in negative work behaviors and performance. The current review is an attempt to highlight salient features of normative commitment so that it could help policymakers to control deviating behavior of employees. Review analysis shows that two-face theory does not support the bi-directional concept of normative commitment rather motivational theory supports the uni-dimensional concept of normative commitment. Furthermore, NC profile faces validity problems which two faces theory is failed to explain. Also, high NC/AC profile is not favorably related to positive work outcomes as compared to AC profile only. Normative commitment profile changes its effects on other commitment profiles. If AC is loud, NC profile is experienced as good duty face while, if CC is high then NC profile is experienced as indebted obligation face. At the end of the study, research implications have been discussed. Future scholars need to focus more on the two-face concept of normative commitment to getting a clear picture of this profile.
\end{abstract}

Keywords: Commitment, Normative commitment, Two-faces, Self-Determination Theory

\section{Introduction}

The organizational commitment had gained much interest of scholars when they intended to study organizational behavior. In one of the meta-analysis by Cooper-Hakim and Viswesveran (2005), they stated that more than five hundred articles had been published on commitment over the past 20 years. Though, some similar constructs, like job embeddedness, work engagement and psychological attachment (Jaros, 2009), have been introduced by scholars but still this concept is getting more and more critical because of its implications and strong linkages with different employee behaviors and attitudes such as citizenship behavior, turnover, turnover intentions and job satisfaction (cf. Klein, 
Becker, \& Meyer, 2009). Three component model of organizational commitment has gained much fame in commitment research. Allen and Meyer (1990) are the pioneers to introduce this multidimensional concept of organizational commitment. According to them, employees show attachment with the organization because of effective (based on emotions), continuance (costbenefit analysis) or normative (sense of moral obligation) commitment. This model has been used extensively in theoretical and empirical research (Xu \& Payne, 2016) and is used to study not only commitment but other foci like occupations, team, and supervisors (Morin et al., 2011). Despite contradictory remarks by Klein, Molloy, and Brinsfield (2012) regarding its validity, many research is using this conceptualization to examine commitment of individuals in different settings (Xu \& Payne, 2016; Meyer, Morin, \& Vandenberghe, 2015; Meyer \& Matlin, 2010).

Though existing research has proved the general validity of commitment, however, each dimension needs to be equally validated. Affective commitment has strong empirical foundations (Klein, Becker, \& Meyer, 2009) as compared to the continuance and normative commitment. In a few studies, dimensions of Continuance commitment are subject to the certain contradictions (Jaros \& Culpepper, 2014) except one dimension "high sacrifice" (Powell \& Meyer, 2004). Contrary to it, normative commitment is dealt with several practical problems throughout the history. Bergman (2006) noted that when affective commitment is controlled, it fails to explain the attitudinal outcomes of individuals. In addition to this, Jaros (2007) noted that there is lack of coherence in the definition of normative commitment and measurement scale as items were not actually describing this construct instead they seemed to be part of continuance commitment (Powell \& Meyer, 2004) and not the separate dimension of commitment (Cohen, 2007). Due to this criticism, there is substantial need to validate NC construct to decide its belongingness to commitment construct.

After such heavy criticism, Meyer and Parfyonova (2010) gave explanatory notes to defend NC construct and confirmed its validity as being part of a multi-dimensional concept of commitment. Their review is wide-ranging and entails comprehensive literature on normative commitment. Gellatly, Meyer, and Luchak (2006) and Meyer, Becker, and Van Dick (2006) already explained a brief overview of normative commitment which is also the central theme of the current review. According to them, traditionally, NC was considered to be a uni-dimensional construct which reflects an individual's moral sense of obligation to stay with the organization, it has two dimensions. One is related to the indebted sense of obligation to stay with the organization, and another one is related to the sense of moral duty. Meyer and Parfyonova (2010) stated that these two dimensions have not only different practical implications for attitudinal outcomes but also provide theoretical support for two faces conceptualization of NC. Thus, they concluded that heavy criticism on NC being its part of commitment profile is based on erroneous conclusions findings. There are several other research findings which have validated two faces concept of normative commitment (Kam et al., 2016).

But the question arises that whether the dual nature of NC profile as defined by Meyer and Parfyonova (2010) and others is correct or not? The current paper aims to analyze the dual nature of NC construct critically. In the first part, the reconceptualization of commitment literature is discussed. In the next phase, Meyer and Parfyonova's dual nature of NC is critically analyzed. Next, their 
INTERNATIONAL JOURNAL OF ACADEMIC RESEARCH IN BUSINESS AND SOCIAL SCIENCES Vol. 8, No. 11, Nov, 2018, E-ISSN: 2222-6990 @ 2018 HRMARS

theoretical justification for dual nature is reviewed. Finally, research implications and future directions regarding three-component model (TCM) are offered for future scholars.

\subsection{Two faces of Normative Commitment}

Gellatly, Meyer, and Luchak (2006) intrigued the two faces of normative commitment. They tested the hypothesis developed by Herscovitch and Meyer (2001) which they aimed to examine the combined effect of affective, continuance and normative commitment to different employee behaviors. Same like other studies, it was found that high levels of affective commitment results in a strong affiliation with the organization which in turn improves citizenship behavior of employees and reduces turnover. Further, they noticed that high levels of continuance and normative commitment have different effects on these behaviors. The reason is that affective commitment results due to employee's inner feeling to make a commitment which creates positive bonding with the organization while CC results due to external forces which arouses fear of costs in case employee are intended to leave, and normative commitment also results due to compelling external forces which bind individuals with an organization. According to Herscovitch and Meyer (2001) when all three forms of commitment are high, then normative and continuance commitment affects the internal feeling of attachment which in turn reduces the impact of AC on positive employee behaviors. It means that high affective commitment profile positively impacts turnover and organizational citizenship behavior than that of high commitment profiles of all three forms or high level of AC and either of the profile and low level of another form of commitment.

Contrary to it, Gellatly et al. (2006) found that high levels of affective and normative commitment (and low levels of CC) help in lowering turnover intentions and improving citizenship behavior. They further noticed that normative commitment has a negative impact on citizenship behavior when CC is high, and AC is low. To explain this, Gellatly et al. (2006) stated that normative commitment has two faces, one is related to indebted obligation, and other is associated with the moral sense of obligation towards their organization. The indebted obligation increases in the presence of high levels of NC and CC while AC is low because high levels of CC relates to context effect which raises the sense of indebted obligations that creates normative commitment in a negative way. The reason is that continuance commitment is somewhat regarded as a negative form of commitment which compels individuals to stay with the organization due to the high costs of leaving. This, in turn, creates job outcomes for employees if they continue their services.

Contrary to it, high levels of affective commitment create an inner sense of bonding which bounds an individual to stay and improve organizational outcomes. The reason is that high levels of AC cause NC to be experienced as a positive inner feeling which represents our values and hopes for the organization (cf. Meyer, Stanley, \& Parfyonova, 2012). This moral sense of obligation creates positive work outcomes and thus favorably related to citizenship behavior. Lastly, when both AC and CC are high, it is expected that AC would be stronger than CC causing NC to be experienced as a moral sense of obligation towards job (Gellatly et al., 2006). The implication of the dual nature of NC is that when it is a matter of favorable and favorable outcomes like low levels of turnover intentions and high levels of OCB. A commitment profile is characterized by having high levels of NC, and AC (and low 
INTERNATIONAL JOURNAL OF ACADEMIC RESEARCH IN BUSINESS AND SOCIAL SCIENCES Vol. 8, No. 11, Nov, 2018, E-ISSN: 2222-6990 @ 2018 HRMARS

levels of (C) has more significant impacts as compared to high levels of AC profile. Contrary to it, high levels of CC and NC (and low levels of AC) have detrimental, and sometimes harmful, impacts on organizational outcomes as it is associated with the external forces of staying.

Dual nature conceptualizations of NC by Meyer and Parfyonova (2010) resembles Gellatly et al.'s (2006) conceptualization. But Meyer and Parfyonova (2010) negated Gellatly et al.'s (2006) conceptualization in two ways. Firstly, they stated that the two faces concept of NC is supported by several empirical research work done by scholars since the beginning of Gellatly et al. 's, (2006) work. Gellatly et al. (2006) was a pioneer to test Herscovitch and Meyer (2001) conceptualizations of organizational commitment. Though many studies have been published between 2006 and 2011 which shown tremendous efforts in expanding commitment literature, as explained by Meyer and Parfyonova in their study, that normative commitment changes its faces subject to high active or continuance commitment.

2ndly, Meyer, and Parfyonova (2010), with the help of Self-determination theory (1985), attempted to provide a clearer picture of two faces nature of normative commitment. They stated that when high affective commitment and high normative commitment are combined, internally and autonomous self-regulation is observed in employees to commit with the organization which represents a moral sense of duty while the combination of high NC and high CC results into indebted obligation aspect. It arises when external forms of control tend to bind employees towards their work, but employees usually resist it and thus causes low motivation towards work. Just it can be said that employees tend to be more willing to show a positive attitude and motivation towards their work when they feel it internally rather than external forces bind them to do so. In the next section, theoretical and empirical justification of this two face nature of normative commitment is discussed.

\subsection{Two-Faces Analyzed: Empirical Evidence}

Both empirical evidence and theoretical justification support Meyer and Parfyonova's (2010) justification for two-faced nature of normative commitment. Empirical evidence is more important than theoretical justification. The reason is that theoretical justifications only explain empirical evidence which supports two -face concept of NC but if the empirical evidence fails to explain and support the two-face concept, then there remains no need for theoretical justification. In this section, Meyer and Parfyonova's conceptualization of empirical evidence will be evaluated that whether it supports two-face of NC or not. This review may be a subjective evaluation as it interprets some of the Meyer and Parfyonova's conceptualization plus some other studies which were not published at that time. To support this view, Meyer and Parfyonova's (2010) views will be quoted extensively to judge that whether current review's conceptualizations are valid or not. Also, results from other empirical findings are included for better judgment of findings. Results can be seen in Appendix.

Meyer and Parfyonova (2010) cited one of the essential findings of Wasti (2005) in which. In commitment of Turkish employees was studied. Meyer and Parfyonova (2010) stated that Wasti's (2005) findings suggest that commitment and intention to stay was higher in those individuals who were high AC and high NC (and low CC) than other individuals with high AC-dominant profile group. 
Merely stating, normative commitment works more significantly to turnover intentions as compared to affective commitment. While, no significant differences were found between high affective/normative commitment and high affective commitment profiles concerning quitting behavior and job stress. So, for these variables, normative commitment did not play any significant role as compared to affective commitment. It contradicts the idea of normative commitment that if $\mathrm{NC}$ is experienced with high AC, its moral duty component is experienced and intriguers motivational force which impacts positive work outcomes.

In study 2, Wasti (2005) included only high sacrifice items of continuance commitment construct. It was found to be more reflective measures of CC profile than initially developed CC profile developed by Meyer and Allen (1990) which also contains low alternative items too (cf. Jaros \& Culpepper, 2014). The study revealed that high useful/normative commitment profile and affective commitment profiles showed no significant differences over job stress, quitting behavior which again negates the two-face concept. Similarly, high normative/affective commitment profiles do not differ from continuance/normative commitment profiles for the same outcomes. Since two-face concept recognizes normative/affective commitment profile as a state where an individual is internally motivated to stay with the organization. While normative/continuance commitment profile is regarded as an externally driven profile which compels individuals to perform organizational tasks, which clearly shows that high NC/AC profile individuals have low quit intentions and high levels of staying, the findings of the second study contradict two-face concept even more strongly. Wasti (2005) concluded that it is an only affective commitment that contributes towards staying behavior of employees irrespective of normative or continuance commitment as these (high NC and high CC) measures do not contribute significantly when they are integrated with affective commitment. This finding also contradicts the two-face theory.

Meyer and Parfyonova (2010) cited another study of Somers (2009) who studied commitment profiles, job stress and quitting behavior of employees. Somers (2009) found low turnover intention amongst committed and affective/normative-dominant profile groups. The turnover intention was lower for these groups as compared to free and continuance committed-dominant profile groups. Meyer and Parfyonova argue that Somers (2009) find that the affective/normative commitment profile has a low impact on turnover intentions than continuance/normative commitment profile group. Furthermore, he did not find any findings of affective commitment-dominant profile group related to turnover intentions because it did not appear in cluster analysis and thus analysis lacks comparison of this profile. High affective/normative commitment profile is associated with low stress than high continuance/normative commitment profile, the high continuance/normative commitment profile and high affective/normative commitment profiles shown similar findings on absenteeism of employees and it was actually high continuance/normative commitment profile which was related to low absenteeism which again shown contradiction to the two faces theory. Findings of the study provide mix support for the NC/AC profile (characterized by moral duty motivation) and high CC/NC (characterized by indebted obligation). 
In addition to this, Meyer and Parfyonova (2010) cited another study of Somers (2010) in which he examined the relationship between commitment profiles and turnover behavior. Meyer and Parfyonova give remarks on Somers (2010) findings and say that actual turnover rates were found to be lower in committed and Affective/normative-dominant profile groups. This finding supports the dual-face concept. But one of the conclusions of the study contradicts this two faces concept, which is, high effective/normative commitment profile did not differ from high affective commitment profile or continuance/normative commitment profile about absenteeism or turnover behavior. However, high effective/normative commitment profile shown high staying intention scores which is consistent with two faces in theory. In sum, the study provided mix support for the dual-face concept.

Meyer and Parfyonova also cited Marcovitz, Davis, and Dick's (2007) to support the two-face concept. According to Meyer and Parfyonova (2010), the study revealed that highly committed, affectivedominant and affective/normative-dominant commitment profiles shown high levels of intrinsic job satisfaction as compared to continuance/normative-dominant and uncommitted and continuancedominant commitment profiles. This is precisely the same as Marcovitz et al. findings. But these findings also don't fully support the two-face theory. According to the two-face concept, normative/affective commitment profile leads towards high intrinsic job satisfaction as compared to normative/continuance commitment profile. Furthermore, normative/affective commitment profile has high levels of intrinsic job satisfaction as compared to affective commitment profile, both of these findings were not observed in this study.

Corstjens (2011) analyzed two-face conceptualizations in a study to test its implications for undergraduate and graduate students in the Netherlands. Results of the study somewhat supported the dual-face theory. It was found that students with high levels of affective/normative commitment profiles shown high organizational support and autonomy as compared to others who were characterized by high levels of continuance/normative commitment profile. Some of the findings of the study shown contradictory results related to two-face theory. For example, high effective/normative commitment profile shown no significant differences from affective or continuance/normative commitment profile concerning prevention motivational focus, promotion motivational focus, positive affect or adverse effect. All these findings show a contradiction to the perception of Corsten related to the normative commitment that it has two dimensions, i.e., indebted obligation and moral sacrifice.

In another study, Meyer, Stanley, and Parfyanova (2012) analyzed the dual-face concept for HR workers. They conducted a study on human service workers to find out work engagement, general health, positive affect, adverse affect, and autonomy and job satisfaction using latent profile analysis rather thank-means which were used in other studies. It was found that high normative/affective commitment profile shown strong association with positive outcomes when combined with affective commitment profile. But big normative/continuance commitment or high affective commitment profile were not revealed in the sample by latent profile analysis, and thus it made difficult to compare it with two-face conceptualization. 
In another study, Stanley et al. (2013) analyzed the relationship between commitment profiles, turnover intentions and quitting behavior with the help of latent profile analysis (LPA). It is clear that Meyer et al. (2012) could not find the existence of high normative/continuance commitment profile. Comparisons of high affective/normative commitment and high affective commitment profiles did not show any significant differences for turnover intentions or turnover behavior and which indicated that combining, both high affective and high normative commitment does not lead towards moral duty conceptualization. Furthermore, high normative commitment does not help in reducing turnover intentions as compared to high affective commitment profile.

To explore the temporal stability of commitment profiles, Kam et al. (2016) conducted a study using a latent transition analysis (LTA) approach. They analyzed changes in commitment profiles for eight months in an organization. It was found that people showing high affective/normative commitment profile had low turnover intentions as compared to people having high affective commitment profile. One shortcoming of the study was that no high continuance/normative commitment profile was found.

\subsection{Summary of Empirical Research}

Contrary to the findings of Meyer and Parfyonova (2010), findings of current studies show that NC is characterized by moral imperative when it is combined with high levels of AC, but when NC is experienced with CC, the indebted obligation is not observed and is not fully supported. According to two-face theory, high normative and affective commitment profiles are associated with high positive work outcomes than affective commitment profile only. Furthermore, high normative/continuance commitment profile should show a contradiction to the normative/affective commitment profile. These results can be summarized as follows:

High normative/affective commitment vs. high affective commitment profile only: 8 comparisons support the dual-face theory: 18 comparisons shown inconsistent findings

High normative/affective commitment profile vs. high normative/continuance commitment profile: 9 comparisons supported dual face theory: 13 comparisons shown inconsistency with dual face theory.

This result comparison does not support the two-face theory. When comparing high normative commitment/affective commitment and high affective commitment profiles, non-response rate is found to be $69 \%$, and for high normative/affective commitment vs. normative/continuance commitment, $59 \%$ studies do not fully support this concept while only $41 \%$ support is found. The results cannot be favorable as the number of studies under review are very small, and also the methodology for assessing commitment profile is the least valid, i.e., use of median-splits (cf. Kam et al., 2016). In their study, they reported four comparisons in which three comparisons supported the dual-face theory. On the other end, PLA/LTA, the most advanced methodology for assessing commitment profile, was used in three studies and with the help of it, only one comparison supported the two-face theory. These methods also did not reveal the existence of high normative/continuance commitment profile which could give rise to the question that whether employees feel this combination so that its theoretical support could be justified for its inclusion in the theoretical model. 
It is evident from the above literature that Meyer and Parfyonova (2010) conceptualization about two-face nature of normative commitment, first characterized by a moral sense of duty (when high AC profile is experienced) and other one is an indebted obligation (experienced with high CC), is not supported by available studies. Hence, it can be concluded that the two-face concept is not favorably supported in these studies and is inconsistent with the modern research.

One important thing which has been observed in these studies, that is, when normative commitment could not favorably contribute, what high AC is supposed to help, it also did not harm the outcomes of the results showing that affective/normative commitment profile had no lower mean score for favorable work outcomes or higher mean scores for unfavorable work outcomes, which shows that when high NC has no relationship with these outcomes, it at least did not hurt the relationship of high AC with these variables. These results, not supportive of two faces theory, also contradict Meyer and Herscovitch's (2010) findings that high NC tempers the effect of AC, showing that high AC significantly effects work outcomes as compared to high AC/NC profile. What is happening is that normative commitment does not affect the functioning of affective commitment of employees who show positive work behavior and attitudes.

The following section discusses the implications of these findings briefly.

1. Do employees experience high normative/continuance commitment profiles?

As noted earlier, commitment profiles have been assessed with the help of three methods: latent modeling, cluster analysis, and median splits. Among these, latent modeling is one of the most modern methodologies and has advantages over others (cf. Morin et al., 2010). When the results of these studies were compared, two main findings were more prominent regarding methodology. First, methods, which were used to assess commitment profile, did not moderate the relationship between variables, like moral duty face and high AC profile. For example, when turnover related behaviors are assessed either using a lesser method or latent modeling, it was found that both moral duty and high affective commitment profile explain the same level of variance which is roughly $33 \%$. Secondly, the profiles seemed to differ from each other. For example, none of the studies, which used latent modeling, found indebted obligation profile (high normative/continuance commitment profile), while rest of the studies which used cluster analysis or median splits found indebted obligation profile in their studies.

Somewhere is studying, the discrepancy is found in the sense that if employees do not feel a sense of indebted obligation, then this weakens the point that NC profile has two faces. One important finding from these studies is that studies, which used a latent modeling approach and failed to explain indebted obligation face of normative commitment, were published after the emergence of two-face theory. It shows that this theory is based on these questionable outcomes. Thus, it can be said that weakness of two-face theory of normative commitment is due to the application of the irrelevant methodology. This finding, with the help of latent modeling, shows consistent findings when compared with variable-centered research. Studies, which tend to assess individual effect commitment profiles, it is found that normative and affective commitment profiles show significant results while normative and continuance commitment profiles are uncorrelated (Meyer et al., 2002) 
INTERNATIONAL JOURNAL OF ACADEMIC RESEARCH IN BUSINESS AND SOCIAL SCIENCES Vol. 8, No. 11, Nov, 2018, E-ISSN: 2222-6990 @ 2018 HRMARS

which shows that people hardly experience both normative and continuance commitment at high levels showing that these profiles do not appear when the latent modeling approach is used.

\section{Research Implication 1:}

It is clear from these empirical findings that future researchers should use updated possible modeling approaches to assess NC. Though there are very few people have indebted obligation profiles, future researchers need more samples to fully explain the indebted obligation. Approximately 300 to 700 respondents have been examined in which latent modeling approach is applied in past studies. Though these sample sizes are reasonable, yet there are very few individuals who experience high levels of normative and continuance commitment simultaneously. So, it might take larger sample sizes so that indebted obligation profile becomes visible in latent modeling approach if the large sample size is examined.

\section{Research Implication 1b:}

Conversely, it is more likely that individuals who show high indebted obligation profiles are in abundance in some selected type of organizations. It might be the case that employees feel it positive when obligations are imposed on them, and they also have organizational support as well (cf. Somers, 2010), and hence start feeling a moral sense of duty rather than indebted obligation. Thus, future researchers, who intend to compare indebted obligation and moral duty, might consider organizations where employees do not feel the burden when they need to fulfill certain obligations, and they do it in a positive way which others feel certain obligations as bad, but some people unwelcome, such obligations. Such respondents can be found in military and police sector in which both types of profiles can be found easily (cf. Jermier et al., 1991).

\section{Research Implication 1C:}

It is more likely that indebted obligation profiles can be found in the same organization. For example, Etzioni (1961) pointed out that organizations face many administrative problems. Among them is controlling the lower level staff that do not enjoy most of the organizational benefits and usually face a heavy workload. That's why organization face a negative attitude from such employees as they are less involved in organizational activities as compared to upper-level staff that enjoys several organizational benefits and are treated well as compared to low-level employees. That's why lowlevel employees show negative work behavior and outcomes. For this reason, researchers who employed latent modeling approach selected passing out students from university (Kam et al., 2016) and professional medical staff (Meyer et al., 2013) because, unlike un-skilled and unprofessional staff, these two types of respondents should have more moral duty sense as compared to others. Thus, researchers, who intend to compare two face nature of normative commitment, are suggested to take a sample from both upper and lower level staff so that they could get an equal number of profiles from their analysis.

\section{Construct Validity of the Two-Face Theory}

Another issue related to NC is its validity and its relation to two-face theory. Meyer and Allen (1990) were the pioneers to develop this scale. Later on, Meyer and Allen and Smith (1993) revised the 
normative commitment scale but it showed more correlation with affective commitment than that of original scale (cf. Meyer et al., 2002). It is important to note that normative commitment scale has not undergone significant changes and updated itself with advancement in its conceptualizations (Jaros, 2007) as compared to two-face theory. That's why, the items of NC scale, which were created, do not exactly focus neither on moral duty nor indebted obligation.

Concerning revised normative commitment scale, Wasti and Onder (2009) state that it covers both moral duty and indebted obligation profiles. In the revised scale, only two of the items represent obligation like, "I do not feel any obligation to remain with my current employer." Other items represent the feeling of guilt in case one leaves or is intended to leave the organization. So, items in the revised scale, NCS 1993, mostly represent indebted obligation, a sense which individual feels to stay with the current organization as they might lose certain benefits and will have to bear psychological or social costs. Contrary to it, none of the items represent moral duty, an individual's strong desire to stay with the organization which Meyer and Parfyonova (2010) described as an individual's intention to stay because it's the right thing to do.

Thus, it might be the case that the above-mentioned studies failed to reveal the relationship of twoface theory and job correlates only because of NC scale which does not capture both moral duty and indebted obligation profiles. Wasti and Onder (2009), based on the theory of interpersonal behavior (1980), proposed that two faces of normative commitment can be identified when separate scales are used to measure both moral duty and indebted obligation separately. Wasti and Onder (2009) also introduced the concept of personal norms. But this conceptualization is too broad as it is defined as the feelings one have for a particular task but it is unable to explain normative considerations (For example, an employee stays with the organization to collect the pension money). Also, the theory of behavioral intentions is related to an individual's behavioral intentions and not with the commitment of individuals. So, any study based on its findings will be dealt with behavioral intentions. Since commitment research has different findings when compared with behavioral intentions, this might create problems for commitment researchers when two faces concept is meant to explain from such studies (cf. Klein et al., 2012; Jaros, 2009).

From the current debate, it is clear that both versions of normative commitment measurement failed to measure two faces of normative commitment accurately. Thus, to measure that whether the normative commitment is uni or bi-directional, there is a need to need further to elaborate Meyer and Parfynova's (2010) conceptualizations. For example, "I believe it is morally correct to dedicate myself to this organization" clearly shows that it relates to moral duty while "I feel obligated to support this organization even though I would rather not" describes indebted obligation. If the normative commitment scale is revised and separate measurement items are developed for both faces, then it would generate more accurate results for NC. This, perhaps, don't allow our understanding that how affective or normative commitment profiles contribute to two faces of normative commitment. 
Commitment Researchers are still trying to find out that whether it would generate specific results to the theory if separate measurement scales for normative commitment are developed. Most of the current studies have applied different CC scale which, in fact, does not reflect the same measure. Allen and Meyer (1990) first developed the scale to measure continuance commitment. Factor analysis of the construct shows that this construct also shows two different factors, one is related to social and economic sacrifices, one has to make if individual employee intends to leave the organization, another one is related to lack of alternatives (cf. McGee \& Ford, 1987). Commitment researchers suggest that sacrifice sub-dimension relates to continuance commitment while alternatives don't relate (Jaros \& Culpepper, 2014). These commitment scholars suggested removing alternative items from continuance commitment scale while one of the researchers suggested not to exclude alternative items and included all items in their research (cf. Stanley et al., 2013).

The second study of Wasti does not fully support two face theory. She used great sacrifices measure only. Results revealed no significant differences between moral duty and indebted obligation profiles of normative/affective commitment profile for job stress, quitting behavior and turnover intentions. Since these profiles correctly explain moral duty and indebted obligation profiles, so, the study did not support proposed these concepts. Contrary to it studies, which included alternative items, supported two face theory and their ratio for supporting two faces concept is high.

The question arises that why continuance commitment scale does not or produces less favorable results without the inclusion of alternative items? According to two face theory, continuance commitment results due to external forces which compel individuals to stay with the organization. An employee, who wants to leave organization but due to lack of alternatives, employee prefers to remain with the organization which creates bad situation both for employee and organization. On the other end, Powell and Meyer (2004) and Jaros (2007) state that remaining with the organization can be viewed as a positive initiative from the employee. For example, if an employee remains with the current organization only because of a healthy relationship, the employees would positively view this and would sacrifice it if he intends to leave the organization. So, staying with the current employer should be considered by a desire, not by force. Powell and Meyer (2004) found a positive correlation between affective commitment and CC when only sacrifices items were included while results were highly uncorrelated when alternative items were included in the analysis (Meyer et al., 2002). Thus it is not suitable to say that continuance commitment results due to external forces, and it would be more suitable to say that normative commitment is influenced by continuance commitment.

\section{Research Implication 2:}

Commitment researchers who perceive that empirical evidence against two face theory is not convincing and want to resolve this matter must develop new normative commitment scale which fulfills Meyer and Parfynova's (2010) conceptualizations and contains only high sacrifices items of CC. But such research would only generate results which don't support the two-face theory. 
INTERNATIONAL JOURNAL OF ACADEMIC RESEARCH IN BUSINESS AND SOCIAL SCIENCES

Vol. 8, No. 11, Nov, 2018, E-ISSN: 2222-6990 @ 2018 HRMARS

\section{Motivational theory and Two-Face theory}

Meyer and Parfyonova (2010) stated that self-determination theory is an excellent source which provides the basis for the two-faces theory. According to them, SDT explains various forms of motivation. It may result due to lack of autonomy (to avoid punishment), through internal force (one's own desire to work), to regulate full (to achieve goals). It is evident that when one is motivated without any external compulsion, results are more favorable as compared to the situation when individuals are forced to do perform.

According to Meyer and Parfyonova (2010) affective commitment results due to a positive working environment and experiences which derive an inner sense of motivation for staying and is associated with positive work outcomes. On the other end, continuance commitment results due to external workforces which sometimes don't bring positive work outcomes. Contrary to it, they argued that NC has two face personalities which are dependent on the functioning of useful and continuance commitment. If the affective commitment is high, then moral duty sense is experienced by a normative commitment, and favorable job outcomes are observed. On the other end, when continuance commitment is high, normative commitment adopts its indebted obligation face and results in weak job outcomes.

Opposing the Meyer and Parfyonova (2010) view about the normative commitment that it comprises two facets, first is autonomous regulation and other is indebted regulation which is experienced when practical, and continuance commitment react with affect normative commitment respectively but it is argued that normative commitment is a single construct and is not necessarily composed of these two profiles. Deci and Ryan, $(1985,2002)$ consider this introjected regulation between internal and external regulation. On the one end, if an individual has to fulfill other's expectations, it is regarded as external motivation while completing tasks for one's satisfaction will be regarded as internal motivation. According to Meyer and Parfyonova (2010) interjection displays only a negative image of normative commitment, i.e., indebted obligation and is responsible for adverse working outcomes and cannot be linked with organizational citizenship behavior (Gellatly et al., 2006; Meyer et al., 2002).

However, there are equal chances that Meyer and Parfyonova make a mistake in assigning a negative image to introjected regulation. Gausel, Leach, Vignoles, and Brown (2012) suggest introjected regulation as a negative factor as it leads towards discretionary behaviors of individuals. Due to its different nature, it is not necessary that it is related to feelings of guilt and shame. Since such expectations also have some internalized impact, so it reflects individual's values and hopes (cf. Deci \& Ryan, 2002), which help in initiating positive outcomes (Meyer, Becker, and Vandenberghe, 2004). This view relates to classical commitment concept according to which it brings a sense of obligation which is resulted due to normative influences (Meyer \& Parfyonova, 2010: 284). An employee high in normative commitment feels more obligations towards its organization, but there is some role of internal forces as well to accomplish these goals. Thus, as normative commitment proves to be supportive of organizational outcomes but this relationship is weaker than affective commitment 
(Meyer et al., 2002). Sometimes it contributes significantly to organizational outcomes better than affective commitment, but sometimes it fails in doing so.

In sum, self-determination theory provides a sound basis for explaining the relationship of high normative/affective commitment profile in producing favorable work correlates as compared to affective commitment profile only. The uni-dimensional concept of normative commitment also provides similar findings as discussed above that normative/affective commitment profile also relates to favorable work outcomes as compared to normative/continuance commitment profile. If it is supposed that normative commitment has the only single face and does not contain moral duty or indebted obligation, then there will be only reflective differences between high affective and normative commitment and these profiles will have similar favorable work outcomes.

The two-face theory has a significant problem, that is, lack of conceptual support for context effect, a proposed mechanism for which two faces of normative commitment occur. This contextual effect provides a solid basis for normative commitment's profile to be autonomous when affective commitment is high and external when continuance commitment is high. Gellatly et al. (2006) propose that commitment profile of an employee provides a context which influences the functioning of commitment profiles. This context effect proposes that the nature of normative commitment profile changes subject to the strength of other commitment profiles. For example, if the useful commitment is strong, this will cause a normative commitment profile to be more autonomous, but it will lead towards indebted obligation face when continuance commitment profile is high.

But there is no solid explanation behind (a) why there is such change in normative commitment profile when it is subject to high affective commitment and continuance commitment, and (b) why high effective and continuance affect normative commitment's motivational basis but the same effect is not observed in reverse order. Related to (a), there is no specific reason provided by Meyer and Parfynoya that why commitment profiles will create contextual effect due to the experience of other commitment profiles. Self-determination theory also fails to explain the autonomous regulation of affective commitment or indebted regulation of continuance commitment will affect NC's experience of introjected regulation. So, it is not clear that what will be the intensity of affective or continuance commitment profile will influence the normative commitment profile.

Research implication 3:

As it is evident from the above-mentioned literature that normative commitment profile lacks theoretical support for two faces mechanism, it is proposed that in future research using recommendations given in research implications (1), (2a-2c) and (3), two faces concept of normative commitment will be difficult to determine as it is a uni-dimensional profile in real.

\section{Content Validity of the Two-Face theory}

Another explanation for why normative commitment sometimes predicts work-related outcomes above and beyond effective commitment lies in the intense psychological bondage between employee and organization. In its current form, normative commitment might lack content validity. For example, traditionally normative commitment is considered to be formed when a certain sense of obligation arises in individuals (Bergman, 2006), whereas affective commitment results due to emotional factors. Gonzalez and Guillen (2008) are of the view that there are certain good virtues in 
affective commitment profile which make it a more favorable form of commitment. Thus, normative commitment might face restrictions for not having such moral domains which directly impact favorable work outcomes.

Due to this, normative commitment profile needs efforts to explain its variance which is beyond affective commitment profile. According to Meyer and Parfynova (2010), Gonzalez and Guillen's conceptualization of obligation and virtue is roughly aligned with their two face concept. Gonzalez and Guillen's (2008) viewpoints suggest that there is further need to validate both affective and normative commitment profiles. However, Gonzalez and Guillen's conceptualization gains little support about the fact there some elements of moral-virtuous which are embedded in AC (cf. Jaros, 2009). Adding to this, despite consistency with ethics and morality concepts of Aristotle, obligation, and virtue cannot be considered part of commitment profile because obligations can be derived from many sources (cf. Moore, 1922).

This paper adds in the literature that the moral component of commitment should be regarded as a dimension of morality rather than considering the obligatory part. Earlier studies like Kelman (1958), Etzioni (1961), and Kanter (1968) used to commitment profile regarding moral-virtuous form. Later on, the dominance of TCM neglected this conceptualization, and two faces theory became more prominent in commitment literature. Adding to this, Gonzalez and Guillen's (2008) criticism of this classical concept also strengthened TCM concepts. However, the current review highlights certain shortcomings of two faces theory. Also, Klein et al., $(2012,2013)$ introduced the KUT concept of commitment which also weakens the affirmation of two faces theory and strengthens the moral dimension of commitment.

\section{Research implication 4:}

Prior research indicates devotion, dedication, duty, and values as a part of commitment profile. These concepts do not contain an obligatory part, a kind of profile theorized by two faces theory. Hence, both, normative or moral part of commitment is tricky to justify indebted obligation as this concept contains features of continuance commitment. Moral duty concept has roots in emotions and affection, but it is also close to a good idea of responsibility. Thus, commitment scholars can solve the validity problem of two faces theory by (a) considering the uni-dimensional concept of moral duty and (b) by developing the right dimension scale.

\section{Culture and two-face theory}

Commitment research shows that NC is more prominent and shows more favorable work outcomes in collectivist cultures (cf. Bergman, 2006; Meyer \& Parfyonova, 2010) where people respect organizational norms and obligations. In some cases, normative commitment predicts better outcomes than affective commitment (cf. Wasti \& Onder, 2009). The hypothesis of two-face theory, which states that normative commitment gives more work outcomes than affective commitment, is more effective in such cultural contexts (Meyer \& Parfynova, 2010). Adding to this, in collectivist cultures, high normative commitment adds more to positive work outcomes when combined with high continuance commitment profile, which negates the two faces concept. Only two of the studies have been reported which Wasti (2005) reported about Turkish workers as their respondents. But 
INTERNATIONAL JOURNAL OF ACADEMIC RESEARCH IN BUSINESS AND SOCIAL SCIENCES

Vol. 8, No. 11, Nov, 2018, E-ISSN: 2222-6990 @ 2018 HRMARS

the results of the study did not support two faces theory. Future study can be conducted in some other collectivist cultures like China, South Korea, and Indonesia.

\section{Research Implication 5:}

Future researchers should use person-centered research in collectivist cultures, but it is proposed that the normative commitment profile will not yield favorable results related to two faces theory as compared to individualistic cultures.

Conclusion: The future of morals-based commitment

As noted earlier (cf. Bergman, 2006), the normative commitment has been brought forward without identifying validity issues and in an unsystematic way. Though Meyer and Parfynova (2010) attempted to fully explain, with the help of Bergman's (2006) findings, two faces concept of normative commitment but changes in construct requires dealing the issues of construct validity, content validity, and criterion validity. This study shows that normative commitment fails to predict the outcomes as mentioned by two faces theory. Review analysis shows that two faces theory failed to identify validity problems, which become the cause of failure of two faces theory for accurate prediction of normative commitment.

The tough current review shows that, though, two faces theory identified, by Bergman (2006) prediction, validity issues, this construct (normative commitment) still has construct and criterion validity issues which provide a solid basis for failure of two faces theory for prediction of work outcomes. Care should be taken in developing new constructs especially issues of construct and content validity (cf. Jaros, 2009). Though Meyer and Parfynova (2010) presented novel ideas about normative commitment, two faces constructs were developed without sound empirical basis as shown in current analysis somewhat they were based on few studies which lack resemblance with Mayer and Parfynoa (2010) conceptualization. It is equally possible that the, which used median and cluster methods, might mistakenly create indebted obligation profile. Most importantly, both, indebted obligation and moral duty profile were not developed by current empirical research which aimed to analyze their validity. So, commitment scholars should not be surprised by the fact that there is no support for the theory. Adding to this, Klein, Cooper, and Malloy's (2013) first validated Klein et al. 's. (2012) commitment constructs which set an example and showed the way to validate the new commitment constructs.

In sum, it can be concluded that (a) there is not enough empirical support for two faces theory, and (b) uni-dimensional concept is supported by moral-normative theory and motivational theory. There is more space for discussion for the unidimensional concept of commitment, but care should be taken for its validation as discussed by Klein et al. (2013).

Care should be taken in assessing moral commitment concept as there might be several differences among commitment profiles. For example, Cohen (2007) stated that there is ambiguity about commitment measure. Commitment profile is related "propensity to commit" rather than commitment. Allen and Meyer (1990) termed commitment profile as a construct which presents normative commitment as a commitment measure itself. This can be amendable as it is not clear that 
whether normative commitment profile up-brings an employee to socialize enough to stop thinking about quitting the job. Adding to this, Bergman (2006) suggested that it is equally important to consider normative commitment as an antecedent of affective commitment in a sense, which an employee might consider internalized obligations as a desire which he or she was intended to do. It is possible that there is no sufficient empirical research to reject two faces theory. The reason is that there are ten published studies which tested this hypothesis and this number is very small. There are very few studies to show useful insights into this phenomenon. There might be equal chances that these studies got the rejection from the new scholars when extensive research will be done on this hypothesis. For example, Gellatly et al. (2006) first introduced the two faces theory. Later on, heavy criticism was received on it. Due to this reason, it is not necessary that findings of the current review will be appreciated in future research, but it might be that future researchers opt few of the recommendations offered in this review. Furthermore, two faces theory was developed to further explain the normative commitment construct. Since, after the emergence of its validity issue till any future research on this issue, two faces theory should regard NC as a valid form of commitment or due to lack of its complete assessment, normative commitment should be regarded as an ambiguous construct.

Commitment studies are important for management scholars and practitioners. In today's global era, organizations need a strong commitment from their employees to get favorable work outcomes and organizational citizenship behavior to avoid unhealthy work behaviors. Existing research provides useful insights into commitment literature, especially about normative commitment. Lastly, it can be said that outcomes associated with NC are not favorable all the times. So it is not recommended for organizations to emphasize to go for it. However, it is evident that employees do feel moral based commitment in their workplaces. This review is an attempt to rehabilitate salient features of normative commitment to getting useful knowledge about its working and its impact on the work behaviors of employees.

\section{References}

Allen, N. J., \& Meyer, J. P. (1990). The measurement and antecedents of affective, continuance and normative commitment to the organization. Journal of Occupational Psychology, 63, 1-18.

Becker, H. (1960). Notes on the concept of commitment. American Journal of Sociology, 66, 32-40.

Bergman, M. E. (2006). The relationship between affective and normative commitment: review and research agenda. Journal of Organizational Behavior, 27, 645-663.

Cohen, A. (2007). Commitment before and after: An evaluation and reconceptualization of organizational commitment. Human Resource Management Review, 17, 336-354.

Cooper-Hakim, A. \& Viswesvaran, C. (2005). The construct of work commitment: Testing an integrative framework. Psychological Bulletin, 131, 241-59.

Downloaded by University of Newcastle At 03:23 29 March 2017 (PT) 35

Corstjens, K. (2011). The duality of normative commitment. Masters thesis, Maastricht University, The Netherlands.

Deci, E. L., \& Ryan, R. M. (1985). Intrinsic motivation and self-determination in human behavior. New York: Plenum. 
INTERNATIONAL JOURNAL OF ACADEMIC RESEARCH IN BUSINESS AND SOCIAL SCIENCES

Vol. 8, No. 11, Nov, 2018, E-ISSN: 2222-6990 @ 2018 HRMARS

Deci, E., \& Ryan, R. (Eds.), (2002). Handbook of self-determination research. Rochester, NY: University of Rochester Press.

Etzioni, A. (1961). A comparative analysis of complex organizations. New York: Free Press.

Gausel, N., Leach, C. W., Vignoles, V. L., \& Brown, R. J. (2012). Defend or repair? Explaining responses to in-group moral failure by disentangling feelings of shame, rejection, and inferiority. Journal of Personality and Social Psychology, 102, 941- 960.

Gellatly, I. R., Meyer, J. P., \& Luchak, A. A. (2006). Combined effects of the three commitment components on focal and discretionary behaviors: A test of Meyer and

Herscovitch's propositions. Journal of Vocational Behavior, 69, 331-345.

González, T. F., \& Guillén, M. (2008). Organizational commitment: A proposal for a wider ethical conceptualization of 'normative commitment'. Journal of Business Ethics, 78, 401-414.

Hofstede, G., Hofstede, H., \& Minkov, M. (2010). Cultures and Organizations: Software of the Mind. 3rd Edition. New York: McGraw-Hill.

Jaros, S. (2012) Evaluating the "few alternatives" dimension of continuance commitment: A comment on Johnson, Chang, and Yang (2010). Journal of Leadership, Accountability, and Ethics, 9, 114-122.

Jaros, S. 2007. Measurement issues in the Meyer and Allen model of organizational commitment. ICFAI Journal of Organizational Behavior, 6, 7-25.

Jaros, S. J. (2009). Measurement of commitment. In H. J. Klein, T. E. Becker, \& J. P. Meyer (Eds.), Commitment in organizations: Accumulated wisdom and new directions (pp. 347-381). Florence, KY: Routledge/Taylor and Francis Group.

Jaros, S. \& Culpepper, R. (2014). An analysis of Meyer and Allen's continuance commitment construct. Journal of Management and Organization, 20, 79-99.

Jermier, J., Slocum, J., Fry, L., \& Gaines, J. (1991). Organizational subcultures in a soft bureaucracy: Resistance behind the myth and façade of an official culture. Organization Science, 2: 170194.

Kam, C., Morin, A., Meyer, J., \& Topolnytsky, L. (2016). Are commitment profiles stable and predictable? A latent transition analysis. Journal of Management, 42: 1462-1490.

Kanter, R. M. (1968). "Commitment and Social Organization: A Study of Commitment Mechanisms in Utopian Communities". American Sociological Review, 33, 499-509.

Kelman, H. (1958). Compliance, identification, and internalization: Three processes of attitude change. Journal of Conflict Resolution, 51-60.

Klein, H. J., Becker, T. E., \& Meyer, J. P. (Eds.). (2009). Commitment in organizations: Accumulated wisdom and new directions. Routledge/Taylor \& Francis Group, NewYork.

Klein, H., Cooper, J., Molloy, J., \& Swanson, J. (2013). The assessment of commitment: Advantages of a unidimensional, target-free approach. Journal of Applied Psychology, 99, 222-238.

Klein, H., Molloy, J., \& Brinsfield, C. (2012). Reconceptualizing workplace commitment to redress a stretched construct: Revisiting assumptions and removing confounds. Academy of Management Review, 37: 130-151.

Markovitz, Y., Davis, A. J., \& van Dick, R. (2007). Organizational commitment profiles and job satisfaction among Greek private and public sector employees. International Journal of Crosscultural Management, 7, 77-99. 
INTERNATIONAL JOURNAL OF ACADEMIC RESEARCH IN BUSINESS AND SOCIAL SCIENCES

Vol. 8, No. 11, Nov, 2018, E-ISSN: 2222-6990 @ 2018 HRMARS

McGee G W and Ford R C (1987), "Two (or more?) Dimensions of Organizational Commitment: Reexamination of the Affective and Continuance Commitment Scales", Journal of Applied Psychology,72, 638-642.

Meyer, J. P., Allen, N. J., \& Smith, C. A. (1993). Commitment to organizations and occupations: Extension and test of a three-component conceptualization. Journal of Applied Psychology, 78, 538-551.

Meyer, J. P., Barak, I., \& Vandenberghe, C. (1996). Revised measures of affective, continuance, and normative commitment to organizations. Unpublished manuscript. Department of Psychology, University of Western Ontario; London, Ontario, Canada.

Meyer, J. P., Becker, T. E., \& Van Dick, R. (2006). Social identities and commitments at work: toward an integrative model. Journal of Organizational Behavior, 27, 665-683.

Meyer, J. P., Becker, T. E., \& Vandenberghe, C. (2004). Employee Commitment and Motivation: A Conceptual Analysis and Integrative Model. Journal of Applied Psychology, 89, 991-1007.

Meyer, J. P., \& Herscovitch, L. (2001). Commitment in the workplace: Toward a general model. Human Resource Management Review, 11, 299-326.

Meyer, J. P., \& Maltin, E. R. (2010). Employee commitment and well-being: A critical review, theoretical framework, and research agenda. Journal of Vocational Behavior, 77, 323-337.

Meyer, J., Morin, A., \& Vandenberghe, C. 2015. Dual commitment to organization and supervisor: A person-centered approach. Journal of Vocational Behavior, 88: 56-72.

Meyer, J. P., \& Parfyonova, N. M. (2010). Normative commitment in the workplace: A theoretical analysis and re-conceptualization. Human Resource Management Review, 20, 283-294.

Meyer, J. P., Stanley, D. J., Herscovitch, L., \& Topolnytsky, L. (2002). Affective, continuance, and normative commitment to the organization: A meta-analysis of antecedents, correlates, and consequences. Journal of Vocational Behavior, 80, 185-211.

Meyer, J., Stanley, J., \& Parfyonova, N. (2012). Employee commitment in context: The nature and implication of commitment profiles. Journal of Vocational Behavior, 80, 1-16.

Meyer, J., Stanley, J. \& Vandenburg, R. (2013). A person-centered approach to the study of commitment. Human Resource Management Review, 23, 190-202.

Moore, G. (1922). The nature of moral philosophy. Cambridge: Cambridge University Press.

Morin, A. J. S., Morizot, J., Boudrias, J. -S., \& Madore, I. (2011). A multifoci person-centered perspective on workplace affective commitment: A latent profile/factor mixture analysis. Organizational Research Methods, 14, 58-90.

Powell, D. M., \& Meyer, J. P. (2004). Side-bet theory and the three-component model of organizational commitment. Journal of Vocational Behavior, 65, 157-177.

Somers, M. J. (2009). The combined influence of affective, continuance, and normative commitment on employee withdrawl. Journal of Vocational Behavior, 74, 75-81.

Somers, M. J. (2010). Patterns of attachment to organizations: Commitment profiles and work outcomes. Journal of Occupational and Organizational Psychology, 83, 443-453.

Stanley, L., Vandenberghe, C., Vandenberg, R., \& Bentein, K. (2013). Commitment profiles and employee turnover. Journal of Vocational Behavior, 82, 176-187. 
Triandis, H. (1980). Values, attitudes, and interpersonal behavior. In H. Howe and M. Page (editors), Nebraska Symposium on Motivation, 1979 (pp. 195-259), Lincoln, N.E University of Nebraska Press.

Wasti, S. A. (2005). Commitment profiles: Combinations of organizational commitment forms and job outcomes. Journal of Vocational Behavior, 67, 290-308.

Wasti. S. A. \& Onder, C. (2009). Commitment across Cultures: Progress, pitfalls, and propositions. In H. J. Klein, T. E. Becker, \& J. P. Meyer (Eds.), Commitment in organizations: Accumulated wisdom and new directions (pp. 309-346). Xu, X. \& Payne, S. (2016). Predicting retention rates from organizational commitment profile transitions. Journal of Management, published online 4/20/2016. 